\title{
Research on the Correlation Measurement between Markets of Finance and Real Estate in Chinese Mainland and Hong Kong Based on the Copula- GARCH Model
}

\author{
Xin Sui \\ School of Finance \\ Nanjing University of Finance and Economics \\ Nanjing, P.R.China
}

\author{
Tingyun Yan * \\ School of Finance \\ Nanjing University of Finance and Economics \\ Nanjing, P.R.China \\ (Corresponding Author)
}

\begin{abstract}
In this study, the Copula-GARCH model is constructed to measure the correlation between markets of finance and real estate in Chinese mainland and Hong Kong. The corresponding yield rate of financial and real estate index is processed by GARCH model to eliminate the autocorrelation and ARCH effects. The residual series obtained from the corresponding GARCH model are converted to new series through kernel density function. Then, the copula function is used to estimate the correlation coefficient between markets of finance and real estate in Chinese mainland and Hong Kong. The extent of the correlation can be diagnosed from the correlation coefficients. The empirical study shows that there is a certain correlation between marke ts of finance and real estate in Chinese mainland and Hong Kong.
\end{abstract}

Keywords-Copula function; GARCH model; Correlation measurement; Risk spillover

\section{INTRODUCTION}

The development of economic globalization makes financial markets in different countries closer. With the development of modern science and technology, the spread of information becomes more convenient and faster, leading to risk spillover from one market to another market. The risk spillover effect between markets in different regions may be more rapid and sensitive. There is no doubt there is a close correlation between Mainland China and Hong Kong markets. Considering that point, this article aims to make a quantitative measurement by using the copula function. Such measurement allows us to understand the risk spillover situation between these two markets.

\section{LITERATURE REVIEW}

In recent years, risk management has been playing a more and more important role in financial field. The research of risk correlation and contagion between various markets or regions lays a foundation for risk management in a more effective way.

This research is supported by MOE (Ministry of Education in China) Project of Humanities and Social Sciences (No.17YJC630128), Fund Project of Natural Science Research in Colleges and Universities in Jiangsu Province (No.17KJB120005;17KJB120004), Fund Project of Philosophy and Social Science Research in Colleges and Universities in Jiangsu Province (No.2017SJB0233; 2017SJB0234)
While the copula function provides a tool to research the correlation between different markets. We can find that a growing number of scholars use the copula function to research risk contagion. Ren Xianling (2008) applied the copula function to measure the correlation between Minsheng Bank and Pudong Development Bank [1]. Liu Qiongfang (2010) used copula theory to study the dependency model of financial time series introducing multiple variables [2]. Su Fei (2015) combined Garch model with copula function to conduct a risk measurement in investment portfolio, which essentially is an empirical research on risk dependency [3]. Hu Kaiji (2012) introduced copula theory to calculate the tail correlation between two financial time series [4]. Zhang Shuangli (2014) chose copula function to study the fluctuation relevance of international oil price and Chinese stock markets [5].Guo Liwei (2011) applied Granger causality test and the copula function to research stock market correlation in Shanghai, Shenzhen and Hong Kong [6]. Gao Ping (2012) started from the study of the copula function and tail correlation, researching the correlation of stock markets in Shanghai, Shenzhen and Hong Kong in different phases from 1996 to 2011 [7].

\section{EMPIRICAL RESEARCH}

\section{A. The sample data}

In this study, the performance of finance and real estate market in Chinese mainland and Hong Kong is respectively measured by SSE finance and real estate index (SZ) and Hang Sang finance and real estate index (HS). Hang Seng finance and realty index is generated by the sum of Hang Seng finance index and Hang Seng real estate index. The daily closing price for is used during the research, obtaining from CSMAR database. The sample range is from January 2015 to April 2018. The daily logarithmic yield is used during the research, denoted by the following equation:

$$
\boldsymbol{R}_{t}=\boldsymbol{L} \boldsymbol{n} \boldsymbol{P}_{t}-\boldsymbol{L} \boldsymbol{n} \boldsymbol{P}_{t-1}
$$

where $\boldsymbol{P}$ denotes the closing price. Fig.1 and Fig.2 are the corresponding graphs of the yield rates. Fig.1 relates to SZ, while Fig. 2 refers to HS. 


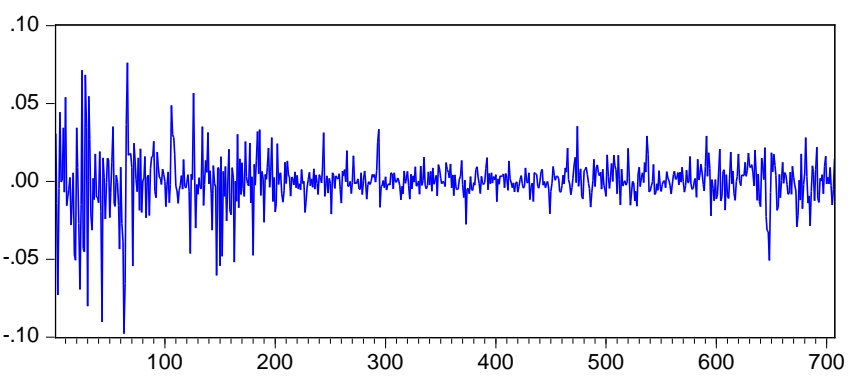

Fig. 1. The index yield rate of finance and real estate market in Shanghai

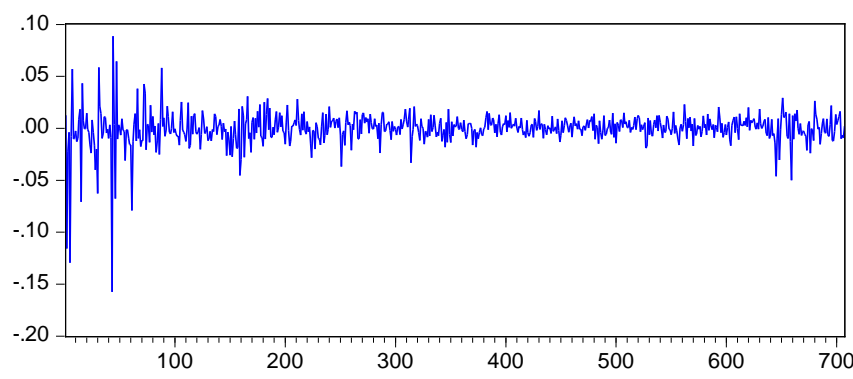

Fig. 2. The index yield rate of finance and real estate market in Hong Kong

From Fig.1 and Fig.2, we can find that a larger fluctuation is followed by a larger fluctuation, which means that there may be volatility clustering effect in both time series. And we will test this phenomenon in the following part of the study.

\section{B. Statistical characteristic of sample data}

Eviews 6.0 is used to obtain the statistical descriptions of the two time series, as shown in TABLE I.

TABLE I. STATISTICAL DESCRIPTIONS

\begin{tabular}{|c|c|c|}
\hline & SZ & HS \\
\hline Average & -0.000187 & -0.000294 \\
\hline Median & $-1.91 \mathrm{e}-05$ & 0.000194 \\
\hline Maximum & 0.076080 & 0.088659 \\
\hline Minimum & -0.097776 & -0.157387 \\
\hline Standard deviation & 0.016232 & 0.016075 \\
\hline Skewness & -0.824916 & -2.568486 \\
\hline Kurtosis & 10.54604 & 28.28981 \\
\hline J-B & 1757.623 & 19618.16 \\
\hline Probability & 0 & 0 \\
\hline
\end{tabular}

It can be seen from TABLE I that the skewness of two time series is less than 0 and the kurtosis is more than 3. Financial data's features of leptokurtosis and fat-tail are reflected in TABLE I. According to the value of $\mathrm{J}-\mathrm{B}$, time series do not obey normal distribution. We can also find this point form Q-Q graph, as shown in Fig.3. In Fig.3, the distributions of two time series both deviate a lot from standard normal distribution.

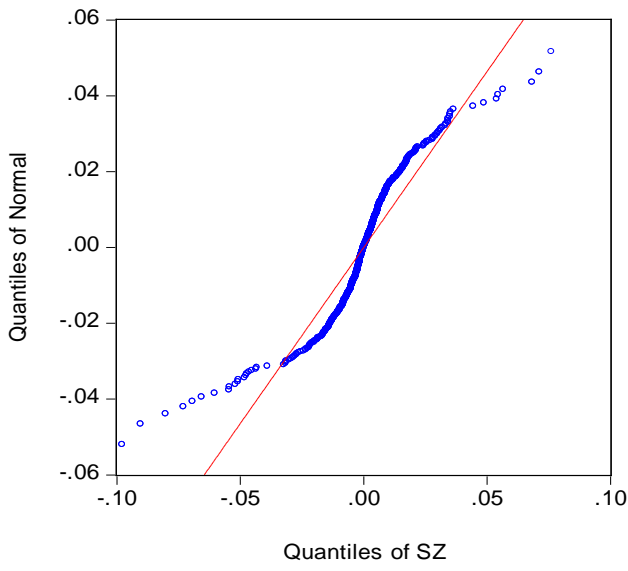

(a)

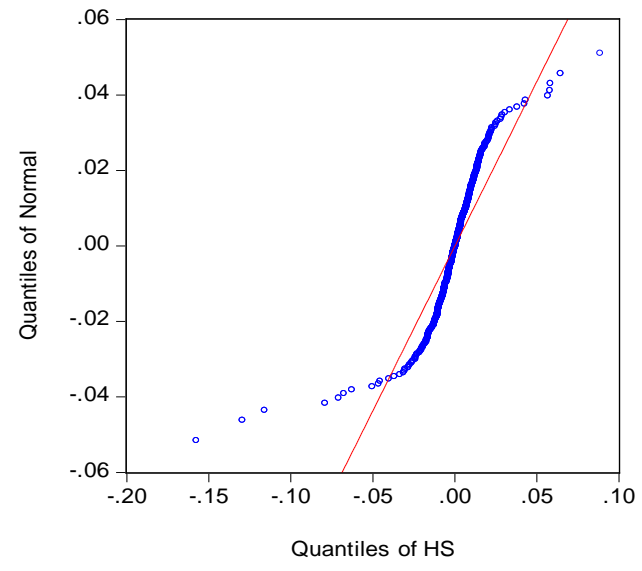

(b)

Fig. 3. Q-Q graphs of the two time series

\section{Establishment of Garch model}

1) The stationary test of time series:

During the research, the time series are required to be stable. Therefore, by using Eviews 6.0, the ADF stationary test is selected to figure out whether the time series are stable. The corresponding results are shown in TABLE II.

TABLE II. THE RESULTS OF ADF TEST

\begin{tabular}{|c|c|c|c|c|}
\hline & & & $\mathrm{t}$ & Probability \\
\hline \multirow{4}{*}{ SZ } & \multicolumn{2}{|c|}{ The critical value of ADF } & -21.38496 & 0.0000 \\
\hline & \multirow{3}{*}{$\begin{array}{l}\text { Confidence } \\
\text { coefficient }\end{array}$} & $1 \%$ & -3.439398 & \\
\hline & & $5 \%$ & -2.865423 & \\
\hline & & $10 \%$ & -2.568894 & \\
\hline \multirow{4}{*}{ HS } & \multicolumn{2}{|c|}{ The critical value of ADF } & -14.04330 & 0.0000 \\
\hline & \multirow{3}{*}{$\begin{array}{l}\text { Confidence } \\
\text { coefficient }\end{array}$} & $1 \%$ & -3.439411 & \\
\hline & & $5 \%$ & -2.865429 & \\
\hline & & $10 \%$ & -2.568897 & \\
\hline
\end{tabular}

From TABLE II, we can find that all the tested series are stationary series and we can use GARCH model directly to fit the two time series. 


\section{2) The autocorrelation and ARCH tests of time series}

The residuals are obtained by using the least square estimation for the time series. Autocorrelation graphs of residuals are shown in Fig.4. It is obvious that Fig.4(a) and Fig.4(b) reveal the feature of autocorrelation for both time series. Fig.5 shows the autocorrelation graphs of time series of the squared residuals. From Fig.5, we can find that both time series takes on ARCH effects. For further research, the autocorrelation and ARCH effects should be dealt with.

\begin{tabular}{|c|c|c|c|c|c|c|}
\hline Autocorrelation & Partial Correlation & & $\mathrm{AC}$ & PAC & Q-Stat & Prob \\
\hline 中 & 中 & 1 & 0.047 & 0.047 & 1.5552 & 0.212 \\
\hline - & - 1 & 2 & -0.153 & -0.155 & 18.184 & 0.000 \\
\hline p & 中 & 3 & 0.056 & 0.073 & 20.384 & 0.000 \\
\hline 1 & ip & 4 & 0.071 & 0.041 & 24.024 & 0.000 \\
\hline$\sqrt{1}$ & $\sqrt{1}$ & 5 & -0.121 & -0.111 & 34.393 & 0.000 \\
\hline ¿ 1 & a & 6 & -0.100 & -0.075 & 41.562 & 0.000 \\
\hline ip & 小 & 7 & 0.036 & 0.007 & 42.509 & 0.000 \\
\hline 1 & 1) & 8 & 0.068 & 0.052 & 45.801 & 0.000 \\
\hline $1 \sqrt{1}$ & 10 & 9 & 0.037 & 0.061 & 46.777 & 0.000 \\
\hline
\end{tabular}

(a) SZ

\begin{tabular}{|c|c|c|c|c|c|c|}
\hline Autocorrelation & Partial Correlation & & $A C$ & PAC & Q-Stat & Prob \\
\hline d & di & 1 & -0.076 & -0.076 & 4.0726 & 0.044 \\
\hline di & L1 & 2 & -0.074 & -0.080 & 7.9885 & 0.018 \\
\hline ص & ص & 3 & 0.208 & 0.198 & 38.754 & 0.000 \\
\hline$\sqrt{1}$ & $\sqrt{1}$ & 4 & -0.067 & -0.045 & 41.910 & 0.000 \\
\hline d & 1 & 5 & -0.056 & -0.037 & 44.144 & 0.000 \\
\hline 1) & 11 & 6 & 0.051 & -0.003 & 45.968 & 0.000 \\
\hline $1 / 1$ & |小 & 7 & 0.003 & 0.024 & 45.974 & 0.000 \\
\hline 14 & 川 & 8 & -0.028 & -0.009 & 46.537 & 0.000 \\
\hline 业 & $1 / 1$ & 9 & 0.013 & -0.002 & 46.659 & 0.000 \\
\hline
\end{tabular}

(b) HS

Fig. 4. Results of autocorrelation tests

\begin{tabular}{|c|c|c|c|c|c|c|}
\hline Autocorrelation & Partial Correlation & & $\mathrm{AC}$ & PAC & Q-Stat & Prob \\
\hline 口 & 口 & 1 & 0.265 & 0.265 & 49.748 & 0.000 \\
\hline שפי & ص & 2 & 0.318 & 0.266 & 121.54 & 0.000 \\
\hline ש曰" & ص & 3 & 0.319 & 0.216 & 193.82 & 0.000 \\
\hline פ & $1 \longdiv { 1 }$ & 4 & 0.168 & -0.005 & 213.86 & 0.000 \\
\hline ص & 吸 & 5 & 0.252 & 0.109 & 259.31 & 0.000 \\
\hline 吋 & , & 6 & 0.099 & -0.066 & 266.28 & 0.000 \\
\hline פ & 1] & 7 & 0.189 & 0.089 & 291.94 & 0.000 \\
\hline פ & 10 & 8 & 0.145 & 0.025 & 307.08 & 0.000 \\
\hline 中 & $1 / 1$ & 9 & 0.093 & -0.003 & 313.23 & 0.000 \\
\hline
\end{tabular}

(a)SZ

\begin{tabular}{|c|c|c|c|c|c|c|}
\hline Autocorrelation & Partial Correlation & & $A C$ & PAC & Q-Stat & Prob \\
\hline صا & ص & 1 & 0.176 & 0.176 & 21.908 & 0.000 \\
\hline$\sqrt{1}$ & $1 / 1$ & 2 & 0.066 & 0.036 & 24.980 & 0.000 \\
\hline 吅 & 口 & 3 & 0.276 & 0.267 & 79.032 & 0.000 \\
\hline ק & $\sqrt{1}$ & 4 & 0.067 & -0.026 & 82.219 & 0.000 \\
\hline $1 \sqrt{11}$ & 1) & 5 & 0.028 & 0.007 & 82.789 & 0.000 \\
\hline$\sqrt{1}$ & di & 6 & -0.003 & -0.090 & 82.796 & 0.000 \\
\hline$\|$ & 1 & 7 & -0.008 & -0.006 & 82.846 & 0.000 \\
\hline 11 & 小 & 8 & 0.004 & -0.000 & 82.858 & 0.000 \\
\hline 1 & ipr & 9 & 0.002 & 0.030 & 82.860 & 0.000 \\
\hline
\end{tabular}

(b)HS

Fig. 5. Results of Arch effect tests

\section{3) The Garch model}

According to the test results mentioned above, the two time series are both stationary and have the characteristics of autocorrelation and ARCH effects. Therefore, the GARCH model is selected to process the data. During the research, the GARCH, TARCH, EGARCH, PARCH and Component
GARCH models are used to fit the corresponding time series. Considering the different residual distribution hypothesis, there are several kinds of models that can be selected such as $\mathrm{XARCH}$ (residual term obeys normal distribution), t-XARCH (residual term obeys t distribution) and GED-XARCH (residual term obeys GED distribution). According to the principle of no autocorrelation, no ARCH effect, maximum likelihood value and the smallest AIC and SC, PARCH $(6,6)$ is applied to SZ time series and $\operatorname{GARCH}(1,1)$ is applied to HS time series. The tests of autocorrelation and ARCH tests are shown in Fig.6 and Fig.7 respectively. Fig.6 refers to the correlograms of the residuals and Fig.7 denotes the results of the correlogram analysis of squared residuals. Form Fig.6 and Fig.7, we can find that the autocorrelation and ARCH tests are eliminated by the selected models for the two time series. Therefore, the selected GARCH models can be used to fit the data and the residuals obtained can be used in the following data process.

\begin{tabular}{|c|c|c|c|c|c|c|}
\hline Autocorrelation & Partial Correlation & & $\mathrm{AC}$ & PAC & Q-Stat & Prob \\
\hline 中 & 中 & 1 & 0.073 & 0.073 & 3.7865 & 0.052 \\
\hline$\sqrt{1}$ & $\sqrt{1}$ & 2 & 0.005 & -0.001 & 3.8020 & 0.149 \\
\hline 川 & 11 & 3 & 0.014 & 0.014 & 3.9411 & 0.268 \\
\hline 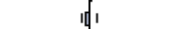 & $\sqrt{1}$ & 4 & -0.041 & -0.043 & 5.1196 & 0.275 \\
\hline , & , & 5 & -0.057 & -0.051 & 7.4447 & 0.190 \\
\hline 政 & 10 & 6 & -0.041 & -0.033 & 8.6231 & 0.196 \\
\hline 1 & iा & 7 & 0.002 & 0.008 & 8.6251 & 0.281 \\
\hline 11 & 11 & 8 & 0.015 & 0.015 & 8.7902 & 0.360 \\
\hline 16 & 1) & 9 & 0.049 & 0.045 & 10.545 & 0.308 \\
\hline
\end{tabular}

(a)SZ

\begin{tabular}{|c|c|c|c|c|c|c|}
\hline Autocorrelation & Partial Correlation & & $\mathrm{AC}$ & PAC & Q-Stat & Prob \\
\hline 中 & 小 & 1 & 0.017 & 0.017 & 0.2138 & \\
\hline 11 & 11 & 2 & -0.023 & -0.023 & 0.5910 & 0.442 \\
\hline 10 & 10 & 3 & 0.026 & 0.026 & 1.0543 & 0.590 \\
\hline 1 & 11 & 4 & -0.007 & -0.008 & 1.0848 & 0.781 \\
\hline$\|$ & 11 & 5 & -0.013 & -0.011 & 1.2007 & 0.878 \\
\hline 11 & 11 & 6 & 0.002 & 0.002 & 1.2045 & 0.944 \\
\hline 川 & 川 & 7 & -0.023 & -0.023 & 1.5834 & 0.954 \\
\hline 11 & 11 & 8 & 0.007 & 0.009 & 1.6182 & 0.978 \\
\hline 川 & 川 & 9 & -0.020 & -0.022 & 1.9140 & 0.984 \\
\hline
\end{tabular}

(b)HS

Fig. 6. Results of autocorrelation tests after modeling

\begin{tabular}{|c|c|c|c|c|c|c|}
\hline Autocorrelation & Partial Correlation & & $\mathrm{AC}$ & $\mathrm{PAC}$ & Q-Stat & Prob \\
\hline p & p & 1 & 0.051 & 0.051 & 1.8790 & 0.170 \\
\hline $1 \sqrt{1}$ & $1 / 11$ & 2 & 0.032 & 0.029 & 2.5944 & 0.273 \\
\hline 1p & י & 3 & 0.037 & 0.034 & 3.5770 & 0.311 \\
\hline $1 / 1$ & $1 / 1$ & 4 & -0.003 & -0.008 & 3.5849 & 0.465 \\
\hline 11 & 11 & 5 & 0.016 & 0.014 & 3.7605 & 0.584 \\
\hline 101 & 101 & 6 & -0.026 & -0.028 & 4.2310 & 0.645 \\
\hline 川 & 川 & 7 & -0.022 & -0.020 & 4.5679 & 0.713 \\
\hline 1 & 11 & 8 & -0.017 & -0.014 & 4.7696 & 0.782 \\
\hline$\|_{1}$ & ון & 9 & 0.020 & 0.024 & 5.0435 & 0.831 \\
\hline
\end{tabular}

(a)SZ

\begin{tabular}{|c|c|c|c|c|c|c|}
\hline Autocorrelation & Partial Correlation & & $\mathrm{AC}$ & PAC & Q-Stat & Prob \\
\hline 10 10 & pr & 1 & 0.039 & 0.039 & 1.0590 & \\
\hline (n) & $\sqrt{1}$ & 2 & -0.030 & -0.031 & 1.6805 & 0.195 \\
\hline 16 & 1 & 3 & 0.037 & 0.040 & 2.6730 & 0.263 \\
\hline 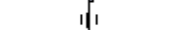 & $\sqrt{1}$ & 4 & -0.022 & -0.026 & 3.0198 & 0.389 \\
\hline 川 & 11 & 5 & -0.011 & -0.006 & 3.1032 & 0.541 \\
\hline 川 & 川 & 6 & -0.013 & -0.015 & 3.2186 & 0.666 \\
\hline 川 & 川 & 7 & -0.018 & -0.016 & 3.4519 & 0.750 \\
\hline 川 & 川 & 8 & -0.023 & -0.022 & 3.8146 & 0.801 \\
\hline 川 & 川 & 9 & -0.012 & -0.011 & 3.9164 & 0.865 \\
\hline
\end{tabular}

(b)

Fig. 7. Results of ARCH tests after modeling 


\section{Correlation measurement based on copula theory}

\section{1) The confirmation of the marginal distribution function}

Based on GARCH models, residuals are standardized to be used as target data in copula function. Before using copula functions to research the correlation between the two markets, the standardized residual series should be transformed to uniform distribution of $U[0,1]$ through the probability integral transformation. The kernel density estimation is chosen to fit the standardized residuals and it is one of non-parametric estimation methods [5].

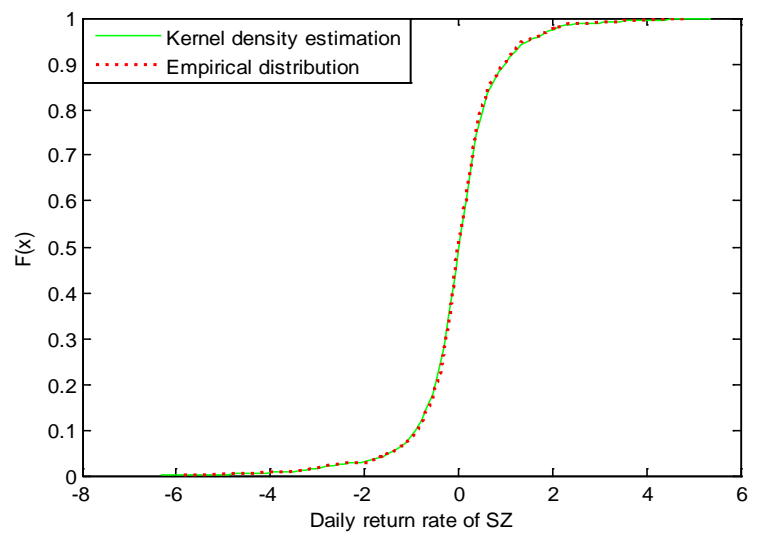

(a) $\mathrm{SZ}$

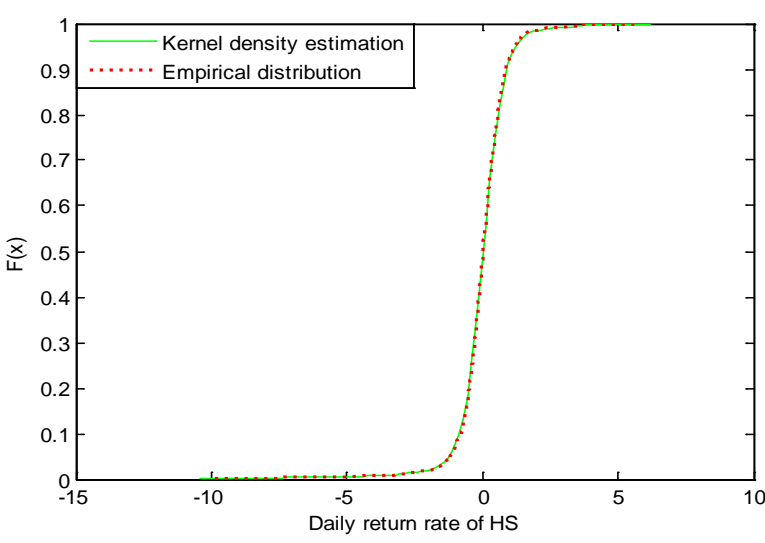

(b) HS

Fig. 8. The graph of two series' estimated kernel density function and empirical distribution function

Using the kernel density estimation, we transform the research data into data from 0 to 1 . Fig.8 reveals the fitting results. In Fig.8, the green solid line represents the result estimated by using the kernel density function and the red dotted line denotes the curve obtained by using the empirical distribution function.

As shown in Fig.8, two time series' distribution curves obtained by using kernel density functions respectively conform to ones obtained by using their empirical distribution functions, which indicates that data transformed by the kernel density function can be well used in copula theory.
2) The study of the data after marginal-distribution transformation

After transforming the data into data from 0 to 1 , we need to test its characteristics. First, we test that whether the transformed data is distributed uniformly. The Q-Q graph is used to test this feature, as shown in Fig.9.

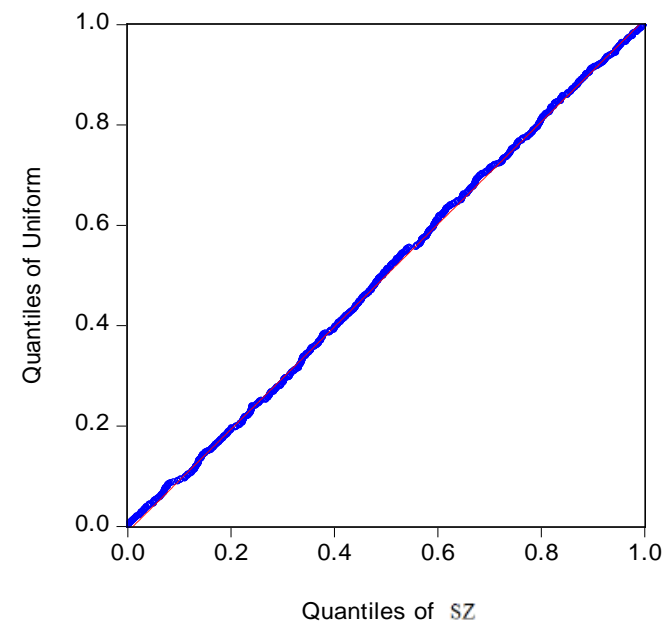

(a)

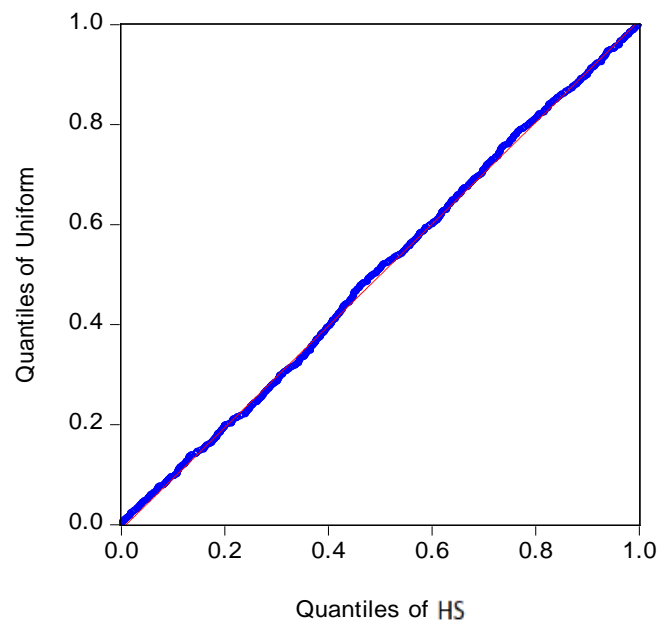

(b)

Fig. 9. Q-Q graph of transformed data

From Fig.9, we can find that the two curves coincide, which indicates the data distributed uniformly.

Then we test the autocorrelation of the transformed data, as shown in Fig.10. Fig10 indicates that there is no autocorrelation in the two time series. 


\begin{tabular}{|c|c|c|c|c|c|c|}
\hline Autocorrelation & Partial Correlation & & $A C$ & PAC & Q-Stat & Prob \\
\hline 10 & 101 & 1 & 0.027 & 0.027 & 0.5049 & 0.477 \\
\hline 11 & 1 & 2 & -0.023 & -0.023 & 0.8687 & 0.648 \\
\hline 11 & 11 & 3 & -0.014 & -0.013 & 1.0038 & 0.800 \\
\hline$\| 1$ & 11 & 4 & -0.023 & -0.023 & 1.3772 & 0.848 \\
\hline 小 & 11 & 5 & 0.016 & 0.017 & 1.5585 & 0.906 \\
\hline 小 & 中 & 6 & 0.018 & 0.016 & 1.7850 & 0.938 \\
\hline 小 & 111 & 7 & 0.019 & 0.019 & 2.0491 & 0.957 \\
\hline 11 & 11 & 8 & 0.003 & 0.003 & 2.0562 & 0.979 \\
\hline 1 & d & 9 & -0.053 & -0.051 & 4.0598 & 0.907 \\
\hline
\end{tabular}

(a) SZ

\begin{tabular}{|c|c|c|c|c|c|c|}
\hline Autocorrelation & Partial Correlation & & $A C$ & PAC & Q-Stat & Prob \\
\hline 小 & 小 & 1 & 0.003 & 0.003 & 0.0079 & 0.929 \\
\hline d & d & 2 & -0.057 & -0.057 & 2.3425 & 0.310 \\
\hline 10 & 10 & 3 & 0.025 & 0.025 & 2.7825 & 0.426 \\
\hline 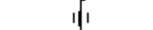 & 1 & 4 & -0.017 & -0.020 & 2.9812 & 0.561 \\
\hline $\mathrm{d}_{1}$ & di & 5 & -0.107 & -0.105 & 11.200 & 0.048 \\
\hline 14 & 蜘 & 6 & -0.044 & -0.047 & 12.596 & 0.050 \\
\hline 11 & 小 & 7 & 0.021 & 0.010 & 12.921 & 0.074 \\
\hline 101 & 101 & 8 & 0.027 & 0.027 & 13.448 & 0.097 \\
\hline שי & 15 & 9 & 0.071 & 0.072 & 17.066 & 0.048 \\
\hline
\end{tabular}

(b) HS

Fig. 10. Autocorrelation test of transformed data

3) The coefficient estimation of copula functions and the selection of the proper copula function

The bivariate frequency histogram of the time series of SZ and HS are obtained in Fig.11. It can help us to determine the selection of proper Copula models. Fig.11 shows that there exists tail correlation between two markets. However, Fig.11 does not give us enough information to determine the type of tail dependences.

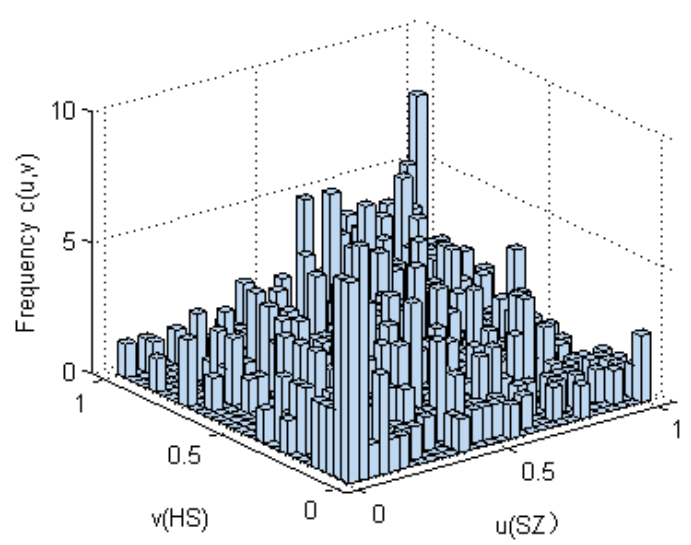

Fig. 11. The bivariate frequency histogram

Under such circumstance, several kinds of copula functions are considered to be used to fit data, including Gaussian copula function, t-copula function, Clayton copula function, Frank copula function and Gumbel copula function. We use the above functions to fit the data and the result is shown in TABLE III, where Kendall $(\tau)$ and Spearman $(\rho)$ are two indicators of correlation measurements.

The smaller the squared Euclidean distance (d) is, the better the model fitting effect is. From TABLE III, we can find that the fitting effect of the t-copula function is better. Therefore, tcopula function is chosen in data analysis. In this model, the values of two correlation indicators are $\tau=0.3178$ and $\rho=0.4616$ respectively.

TABLE III. THE RESULTS OF DIFFERENT COPULA FUNCTION

\begin{tabular}{|c|c|c|c|}
\hline & Euclidean distance(d) & $\tau$ & $\rho$ \\
\hline Gaussian Copula & 0.0503 & 0.2965 & 0.4325 \\
\hline t-Copula & 0.0387 & 0.3178 & 0.4616 \\
\hline Clayton Copula & 0.0573 & 0.2833 & 0.4114 \\
\hline $\begin{array}{c}\text { Frank } \\
\text { Copula }\end{array}$ & 0.0791 & 0.3302 & 0.4802 \\
\hline Gumbel Copula & 0.1181 & 0.2941 & 0.4241 \\
\hline
\end{tabular}

\section{CONCLUSION}

This paper processes the yield rates of SSE finance and real estate index and Hang Sang finance and real estate index by GARCH model. Based on t-copula function, two correlation coefficients are obtained: $\tau=0.3178$ and $\rho=0.4616$, which indicates that a certain correlation exists between SSE finance and real estate index and Hang Sang finance and real estate index.

The finance and real estate market in Chinese mainland started to develop later than Hong Kong. With the continuous deepening of reform and opening, the internationalization of finance and real estate market in Chinses mainland speeds up and the correlation is getting more and stronger with other regions' markets. Hong Kong is one of the developed financial markets in the world and has close connections with many countries and regions in the world. Moreover, a growing amount of mainland enterprises are listed in Hong Kong and Hong Kong investors enter and invest in mainland market. Therefore, the correlation and the risk spillover effect between Chinese mainland and Hong Kong are attracting more and more attentions.

More attentions should be paid to the risk spillover resulted from the correlation of finance and real estate industries in Chinese mainland and Hong Kong, particularly in extreme economic situation. To prevent such potential risk, the first thing which needs to be taken into consideration is to strengthen risk supervision. Not only the financial risk in Hong Kong but also the risk from different regions in the world has the chances to be transferred to mainland via Hong Kong financial market. Once the sign of such kind of risk emerges, more attentions should be paid. Preparations to cope with financial risk need to be made to prevent the expansion of the scope of influence. Risk pre-warning mechanism should be improved and the risk threshold needs to be set in order to take measure in advance to reduce the loss resulted from financial risk. Meanwhile, for participators in financial markets, risk prevention awareness needs to be strengthened. Such practice may help prevent the spread of panic and the acceleration of risk spillover when extreme economic events occur.

\section{REFERENCES}

[1] Ren Xianling, Zhang Shiying. The tail correlation analysis of financial markets based on Copula function [J]. Statistic \& Information Forum, 2008, 23(6): 66-71. (in Chinese) 
[2] Liu Qiongfnag. The research of dependency in financial time series based on Copula theoty [D]. Chongqing University, 2010. (in Chinese)

[3] Su Fei. The empirical research of portfolio risk measurement based on GARCH_Copula model [D]. Shanghai Jiao Tong University, 2015. (in Chinese)

[4] Hu Kaiji. The research of the correlation between Shanghai and Shenzhen 300 index constituent stocks based on Copula function [D]. Shanghai Jiao Tong University, 2012. (in Chinese)
[5] Zhang Shuangli. Correlation analysis of international oil price and Chinese stock market based on Copula function [D]. Anhui University, 2014. (in Chinese)

[6] Guo Liwei. The empirical research of risk spillover and dynamic correlation among Shanghai Stock Exchange, Shen zhen Stock Exchange and Hongkong stock market [D]. Jinan University, 2011. (in Chinese)

[7] Gao Ping. The co-movement analysis of stock markets in Shanghai, Shenzhen and Hongkong based on the study of Copula function [D]. Shandong University, 2012. (in Chinese) 